\title{
Water Everywhere and Not a Drop for Free
}

\section{Spenser W. Havlick*}

School of Natural Resources, University of Michigan, Ann Arbor, Michigan

Only when you look carefully at the enormity of the environmental pollution problem do you realize that the present efforts and funds being expended will not turn the turbid tide which has created pollution of our urban environment. Water resources serve as a case in point. Reference is made particularly to the degraded water quality in the metropolitan complexes of America.

In the past, water either for domestic, industrial or recreational use was not always available but when it was people usually considered it a "free commodity." Today, the technology of water transmission and treatment makes quantities of water available at incredibly low costs. However, water for tomorrows' users will and should have an increasingly higher price tag.

Considerable evidence exists that the attitudes of metropolitan Americans about water resources change very slowly in the absence of a crisis condition. Ineffective planning for floods and droughts are traditional examples. One approach to reduce an increasing spread of water pollution is to be honest with the present student generation. Teachers and other workers with youth must begin to prepare students for the difficulties they face in terms of environmental pollution which will be inherited from us.

Three major points need to be emphasized: 1) Water pollution is the most complex to understand and to combat of all the forms of urban environmental pollution, 2) The cost of water pollution control is the basic reason for the frequency and severity of pollution and 3) If anti-water pollution campaigns are to be waged successfully they must be done on a personal, localized level. The suggestion is made that the youth of America need to become involved with all three of the above considerations if long term water quality improvement can be made.

The urban dweller feels he is more at the mercy of a fouled atmosphere than a fouled river or lake. At the same time sources of air pollution and remedies for its control are relatively simple to identify. For these reasons this author feels that measures to abate air pollution effectively will be taken much sooner than the necessary steps required to reduce water pollution. The complexity of effluents in addition to the complexity of political jurisdictions whose duty it is to monitor and control water pollution make water pollution reduction efforts gigantic tasks in large metropolitan areas (where $72 \%$ of Americans live).

\footnotetext{
- Dr. Havlick is an Assistant Professor in the Department of Resource Planning and Conservation.
} 
Most water pollution problems are created very simply: one water user deciding to save himself the expense of cleaning up the water he uses passes the cost of cleaning up that water on to the next water user. Consider any illustration of a water polluter that comes to mind. $\mathrm{He}$ is extracting a benefit from the use of water without paying the full cost of returning his used water to the waterway in the same quality he found it.

Positively stated, a person, industry, or city that is not a polluter is using the resource (air or water for example) and returning it to the system in a similar or improved quality from its previous condition. This action provides for greater use or more users of the water resource. To perform the task of treating waste water is ordinarily a very expensive procedure. It follows then that most persons, industries or municipalities who can use water and return it without incurring extra costs will do so in the absence of public attention or public pressure.

The time is at hand when an informed citizenry should investigate the actual costs of poorly managed water resources. The findings would help determined who should be encouraged to exercise a more equitable stewardship of a waterway which could have a large number of uses and users if managed more effectively. A plea is submitted that youth be encouraged to participate in the study of water polluters, water cost bearers and the subsequent beneficiaries. It is the youth of the land that will turn the tide of polluted waters in the decades ahead. It is the youth of today who will be paying the bill for high quality water tomorrow. If the decision-makers of the future decide they are unwilling to pay the necessary costs for clean water the miracle of our democracy will provide them with an aquatic environment replete with the filth, disutility and squalor that the negligent deserve.

If anti-water pollution campaigns are to be successfully waged (and we suspect they will be) they must be done so at a local level. Neither youth or adults readily identify themselves with a state or regional effort. The attention and energy of persons are captivated most easily if the issue of water pollution is a local problem which touches their own lives and activities directly. Who isn't going to feel motivated to action when his favorite beach or fishing site is closed because of pollution? Who isn't going to clamor when he finds that his water bill is $25 \%$ higher because a nearby industry is polluting a raw water supply and consequently increasing water treatment costs for each taxpayer?

Soon the question comes up, what can busy teachers and students do in light of a problem as complex and massive as water pollution? Recently a survey was made of major metropolitan newspapers, se- 
lected state and metropolitan school systems and national youth organizations. The major objective of the inquiry was to discover what youth are doing in the area of water pollution investigations and abatement activities. Questions that were addressed to all the respondents requested "a specific description and geographical location of the project, how and why the task was initiated, what youth were involved and what reasons could be given for the failure or success of the project if the water pollution investigation or program is completed."

The results from this brief national survey are alarming and I hope protests can come forth to repudiate the evidence that has come to my attention from the respondents. The majority of replies indicate that the respondent had no knowledge about youth activities involved with water pollution problems. Our research of youth activities in pollution projects continues and suggestions for what can be done by teachers and students are being accumulated.

At the 1967 American Association for the Advancement of Science meeting in New York City many project suggestions were discussed in the Education Section entitled "Man and Urban Society." Some activities included a) biological surveys of the local lake or stream to identify pollution tolerant and pollution intolerant species, b) efforts to identify the source and reason for severe pollution loadings, c) river tours and clean up campaigns where fun and productive work are combined, and d) a water quality monitoring system. A few members of the audience objected vigorously when it was suggested that high school classes or other youth groups collect and analyze water quality data that were also being collected and analyzed by local health authorities.

It is the conviction of this observer that an opportunity for improvement of data collection and interpretation is provided in this kind of competitive setting. Let us assume that rather different results are reported by a local pollution control agency and an investigating youth group under capable adult guidance. A high school chemistry class may come up with detergent concentrations quite different from a health department sample collected at the same time, same place and under the same conditions. Presumably someone's technique or procedure is in need of improvement. If not, an explanation for different results will, at the very least, be educational.

The example above should not imply that all youth investigations need to be "watchdog" operations. Student research projects should be encouraged in areas where no data have been generated before. One notion that may hold special appeal for mathematics classes or clubs is a calculation of the "carrying capacity" of a river. Perhaps it is not widely known that every stream under given oxygen, volume, 
velocity, area, and temperature conditions has a calculable capacity to receive waste materials. Once the stream is overloaded beyond its capacity to assimilate pollutants well known "pollution conditions" become apparent.

Of course over time and distance if the pollution reduction capacity of the river has not been "bankrupted" the quality improves and cities and industries downstream are able to use the "water purification" capacity of the stream up to a mathematically predictable level. For less advanced classes, one water quality variable i.e. oxygen, carbon dioxide, or temperature over a given distance can be studied preferably on a reach of a river in the home town where unsatisfactory river conditions may sometimes exist. The formula and procedures for this activity are described elsewhere and are readily adaptable to most flowing water situations including situations where tides and reservoirs are involved.

The payoff for the urban youth involved in water pollution investigations is not only in terms of the adult eyebrows that are certain to be raised. The rewards will be evident in the attitudes of adults who as youth become inquisitive about real, local problems, and participated in working toward solutions. Adults who have a better understanding about the interrelationships of the natural environment stand in a position to make better decisions (even if they are costly) about managing the total environment. Well informed man as he manages his environment usually gets what he deserves in proportion to his input of interest, effort and dollars.

The real tragedy in the stewardship of our environment would not be that teachers, youth leaders, and parents have failed to correct the problem themselves. Instead the certain calamity would be if those of us who are workers with youth did not come up with innovations to inspire the youth and/or provide an opportunity or framework of operation where youth could help themselves and at the same time provide some learning for adults.

We must encourage youth not to be complacent about water resources, and not to be stingy in their investments which will enhance the quality of the environment. We desperately need fresh organizational inventions, additional dollars, and new priorities for managing an ingredient of our daily lives that we have taken for granted and falsely assumed to be free. 